\title{
DETERMINATION OF HEXAVALENT CHROMIUM ADSORPTION KINETICS AND EQUILIBRIUM ISOTHERMS IN AQUEOUS SOLUTIONS CONTAINING ACTIVATED COCONUT SHELL CHARCOAL
}

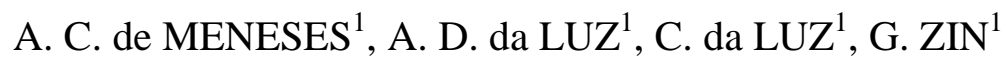 \\ ${ }^{1}$ Universidade do Estado de Santa Catarina, Departamento de Engenharia de Alimentos. \\ aleessandrameneses@gmail.com
}

\begin{abstract}
Hexavalent chromium has toxic and carcinogenic effects and is often found contaminating in surface waters. In the present study, coconut shell charcoal (CSC) thermally and chemically activated with acetic acid was used for the removal of $\mathrm{Cr}(\mathrm{VI})$ from aqueous solutions. The increase in temperature reduced the adsorption capacity, indicating exothermic adsorption. Adsorption kinetics was best analyzed for pseudo-second order model exhibited the best correlation coefficient $\left(R^{2}=0.99\right)$ and proved the most efficient in describing the adsorption rate. The Langmuir-Freundlich isotherm demonstrated the best fit to the experimental data $\left(R^{2}=0.99\right)$ to describe the adsorption equilibrium of $\mathrm{Cr}(\mathrm{VI})$ at different temperatures. The $\Delta G^{\circ}$ value was negative, which confirms the viability and spontaneity of the adsorption process. The present findings demonstrate that CSC thermally and chemically activated with acetic acid proved efficient and can be used for the treatment of waters containing $\mathrm{Cr}(\mathrm{VI})$.
\end{abstract}

\section{INTRODUCTION}

The contamination of water resources due to the indiscriminate discarding of heavy metals has caused concern throughout the world in recent decades (Wan Ngah and Hanafiah, 2008). Chromium, copper, lead, mercury, cadmium, nickel, zinc and iron are significantly toxic to humans and many other life forms (Meena et al., 2005; Mohan and Gandhimathi, 2009). Hexavalent chromium is reported to be a major contaminant of surface waters due to its presence in effluents produced in the galvanization, tannery, cement, dye, fertilizer and photography industries (Jing et al., 2011; Karthikeyan et al., 2005). Demographic expansion and economic activities in industry and agriculture have led to a situation in which no sources of surface water are considered safe and treatment is therefore necessary (Richter and Netto, 1991).

The purpose of the present study was to evaluate the removal of $\mathrm{Cr}(\mathrm{VI})$ from synthesis aqueous solutions using thermally and chemically activated CSC as the adsorbent. A kinetic study was carried out to describe the adsorption rate, using pseudo-first order, pseudo-second order and intraparticle diffusion models. The Langmuir, Freundlich and Langmuir-Freundlich isotherm models were used to describe the adsorption equilibrium between the adsorbate and adsorbent and determine the maximum adsorption capacity of the absorbent analyzed. 


\section{MATERIALS AND METHODS}

\subsection{Preparation of adsorbent and solutions}

Activated CSC was obtained from the Indústria Química Carbomafra S/A (Curitiba, Paraná, Brazil). Solutions containing hexavalent chromium were prepared with potassium chromate salt $\left(\mathrm{K}_{2} \mathrm{CrO}_{4}\right)$ (VETEC). The thermal activation step was performed by the company that supplied the material. The chemically activation was realized with $1 \mathrm{M}$ solution of acetic acid at a proportion of 30:3 and shaken for $3 \mathrm{~h}$. The excess acid was then removed and then dried at $383 \mathrm{~K}$ for $3 \mathrm{~h}$.

\subsection{Characterization of adsorbent}

The characterization of the adsorbent was performed based on the following assays: particle size, hardness, moisture content, volatile matter, ash and fixed carbon. Boehm's titration method was used to functional groups determination (Boehm, 2002). The BET and $\mathrm{BJH}$ tests were performed to determine the surface areas of the material. Scanning electron microscopy was performed to obtain micrographs of the physical structure.

\subsection{Effect of $\mathrm{pH}$}

CSC was first submitted to tests with and without chemical activation with solutions of $30 \mathrm{mg} . \mathrm{L}^{-1}$ of $\mathrm{Cr}(\mathrm{VI})$ were submitted to a $\mathrm{pH}$ range from 2 to 10 . Three $\mathrm{g}$ of adsorbent were added and the mixture was shaken at $135 \mathrm{rpm}, 298 \mathrm{~K}$ for $3 \mathrm{~h}$.

\subsection{Kinetic study}

Batch assays were carried out with three different concentrations of the $\mathrm{Cr}(\mathrm{VI})$ ion (10, 20 and $30 \mathrm{mg} . \mathrm{L}^{-1}$ ) and $3 \mathrm{~g}$ of adsorvent, the flasks were shaken at $135 \mathrm{rpm}$ and $25^{\circ} \mathrm{C}$. One aliquot of each concentration was removed every 5 min then analyzed the concentration in UV-Vis spectrophotometer until equilibrium was achieved. Pseudo-first order, pseudo-second order and intraparticle diffusion models were used for modeling the kinetics of $\mathrm{Cr}(\mathrm{VI})$ adsorption. All experiments were performed in duplicate.

\subsection{Equilibrium study}

Batch using 10 to $50 \mathrm{mg} . \mathrm{L}^{-1}$ at intervals of $5 \mathrm{mg} \cdot \mathrm{L}^{-1} \mathrm{Cr}(\mathrm{VI})$ ion, with $0.5 \mathrm{~g}$ adsorbent were submitted to a thermostat shaker at $135 \mathrm{rpm}$ and at 298, 303 and $308 \mathrm{~K}$. After equilibrium each solution was quantified using UV-Vis spectrophotometry. The amount of $\mathrm{Cr}(\mathrm{VI})$ per unit of adsorbent mass was calculated by following Equation 7, in which $V$ is the volume of the $\mathrm{Cr}(\mathrm{VI})$ solution $(\mathrm{L}), C_{o}$ and $C_{e}$ are respectively the initial and final concentrations (mg. $\mathrm{L}^{-1}$ ) of $\mathrm{Cr}(\mathrm{VI})$ in the solution and $W$ is the mass (in $\mathrm{g}$ ) of the adsorbent.

$$
q_{e}=\frac{V\left(C_{o}-C_{e}\right)}{W}
$$

The equilibrium isotherms of the adsorption in the absorbent-chromium ion system were determined using the Langmuir, Freundlich and Langmuir-Freundlich equations. 


\section{RESULTS AND DISCUSSION}

\subsection{Characterization of adsorbent}

The charcoal available for analysis was classified in the 18 to 20 Tyler mesh range. The CSC exhibited low moisture $(0.03 \% \mathrm{DB})$ and ash content $(1.40 \% \mathrm{DB})$ as well as large amount of fixed carbon $(94.99 \%$ DB). The adsorbent also exhibited a large surface area $(724$ $\left.\mathrm{m}^{2} \cdot \mathrm{g}^{-1}\right)$ and a vast volume of pores $\left(0.39 \mathrm{~cm}^{3} \cdot \mathrm{g}^{-1}\right)$, demonstrating adequate adsorption properties for the removal of contaminants from aqueous solutions. The element analysis revealed that the adsorbent was made up mostly of carbon $(76.64 \% \mathrm{DB})$ following by oxygen $(9.15 \% \mathrm{DB})$ and little concentrations of magnesium, aluminum, silicon, potassium, iron, (respectively, $0.85,2.16,2.38,1.22,7.59 \% \mathrm{DB}$ ). The functional groups found on the surface of the coconut shell charcoal were basic groups in predominance $\left(8.19 \times 10^{-4} \mathrm{mEq} / 100 \mathrm{~g}\right)$, following by total acid groups $\left(2.86593 \times 10^{-4} \mathrm{mEq} / 100 \mathrm{~g}\right)$, phenols groups $\left(2.43 \times 10^{-4}\right.$ $\mathrm{mEq} / 100 \mathrm{~g})$ and lactones groups $\left(4.35 \times 10^{-5} \mathrm{mEq} / 100 \mathrm{~g}\right)$. Characterization in Dry Base (DB).

Images of the charcoal surface were obtained through SEM at magnifications of 30 and $250 \mathrm{X}$ for the morphological characterization are shown in Figure 1. The CSC demonstrated satisfactory morphological characteristics due to the lamellar structure obtained via the activation process.


Figure 1 - Scanning electron microscopy: (a) magnification $30 \mathrm{X}$; (b) magnification $250 \mathrm{X}$.

\subsection{Effect of $\mathbf{p H}$}

CSC activated with acetic acid $1 \mathrm{M}$, there was found a reduction in the capacity to adsorb $\mathrm{CrO}_{4}^{-2}$ from 99.88 to $98.99 \%$ with the increase of $\mathrm{pH}$ from 2 to 10 due to the presence of $\mathrm{OH}^{-}$groups. However, the difference between $\mathrm{pH} 7$ and 2 (which exhibited the greatest adsorption capacity, 99.64 and $99.88 \%$ respectively) was only $0.26 \%$. Thus, the remaining tests were performed using the natural $\mathrm{pH}$ of the solution (7.0). In contrast, with the natural charcoal no $\mathrm{Cr}(\mathrm{VI})$ removal occurred due to the basic characteristic of the adsorbent to repel the chromate anion.

\subsection{Adsorption kinetics}

Pseudo-first order and pseudo-second order kinetics: The pseudo-first order linear equation is displayed in Equation 2 (Meena et al., 2005; Kobya et al., 2005) and the pseudosecond order linear equation is expressed by Equation 3 (Meena et al, 2005; Kobya et al., 2005). Where $k_{l}\left(\mathrm{~h}^{-1}\right)$ and $k_{2}\left(\mathrm{~g} \cdot \mathrm{mg}^{-1} \mathrm{~min}^{-1}\right)$ are the velocity constant of each model, $q_{e}\left(\mathrm{mg} \cdot \mathrm{g}^{-1}\right)$ 
is the amount of solute adsorbed at equilibrium and $q_{t}\left(\mathrm{mg} \cdot \mathrm{g}^{-1}\right)$ is the amount of solute adsorbed at any time $t$, Figures $2 \mathrm{a}$ and $2 \mathrm{~b}$ following both equations.

$$
\log \left(q_{e}-q_{t}\right)=\log \left(q_{e}\right)-\frac{k_{1}}{2.303} t \quad, \quad \frac{t}{q_{t}}=\frac{1}{k_{2} q_{e}^{2}}+\frac{1}{q_{e}} t
$$

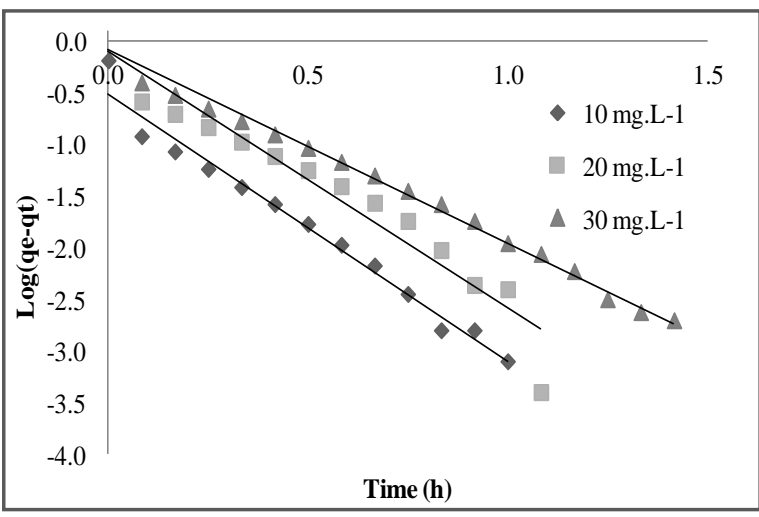

(a)

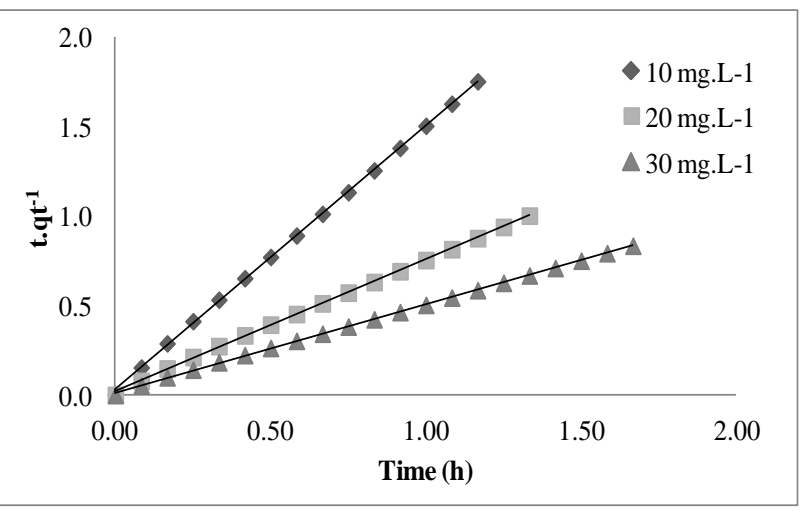

(b)

Figure 2 - Representation of pseudo-first order kinect (a) and pseudo second order kinetic fit (b)

As seen in Table 1, findings indicate that adsorption follows the pseudo-second order kinetic model with correlation coefficients is $R^{2}=0.99$ at all concentrations. There is a strong indication that the velocity limiting step may be of a chemical nature, involving valence forces through the sharing or exchange of electrons between the adsorbent and adsorbate (Mohan and Gandhimathi, 2009).

Table 1 - Parameters of $\mathrm{Cr}(\mathrm{VI})$ adsorption kinetics

\begin{tabular}{|c|c|c|c|c|}
\hline \multirow[b]{2}{*}{$C_{o}$} & \multicolumn{2}{|c|}{ Pseudo-first order model } & \multicolumn{2}{|c|}{ Pseudo-second order model } \\
\hline & $k_{l}\left(\mathrm{~h}^{-1}\right)$ & $R^{2}$ & $k_{2}\left(\right.$ g. $\left.\mathrm{mg}^{-1} \mathrm{~h}^{-1}\right)$ & $R^{2}$ \\
\hline 10 & 7.053 & 0.97 & 75.58 & 0.99 \\
\hline 20 & 6.389 & 0.96 & 28.39 & 0.99 \\
\hline 30 & 5.196 & 0.96 & 19.42 & 0.99 \\
\hline \multirow{3}{*}{$C_{o}$} & \multicolumn{4}{|c|}{ Intra-particle diffusion } \\
\hline & \multirow{2}{*}{$k_{i n}\left(\mathrm{mg} \cdot \mathrm{g}^{-1} \mathrm{~h}^{-1}\right)$} & Stage 1 & Stage 2 & Stage 3 \\
\hline & & $R^{2}$ & $R^{2}$ & $R^{2}$ \\
\hline 10 & 0.782 & 0.95 & 0.97 & 0.84 \\
\hline 20 & 1.462 & 0.94 & 0.98 & 0.82 \\
\hline 30 & 1.982 & 0.96 & 0.97 & 0.87 \\
\hline
\end{tabular}

The results suggest that $\mathrm{Cr}(\mathrm{VI})$ adsorption to CSC occurred due to the electrostatic attraction between the $\mathrm{CO}_{4}^{-2}$ ions and the surface of the positively charged adsorbent through chemical activation with acetic acid. A number of authors (Anandkumar and Mandal, 2009; Duranoglu et al., 2012; Park et al., 2007) report that the adsorption mechanism may be based on the ionic equilibrium between $\mathrm{Cr}(\mathrm{VI})$ and $\mathrm{Cr}(\mathrm{III}) . \mathrm{Cr}(\mathrm{VI})$ anions are bound to positive charges on the charcoal surface stemming from the functional groups $(-\mathrm{COOH},-\mathrm{OH}$ for coconut shell charcoal) and/or chemical activation. 
Intra-particle diffusion kinetics: The intra-particle diffusion kinetics was determined by Equation 4 (Wu et al., 2001), in which $k_{\text {in }}$ is the velocity constant of intra-particle diffusion.

$$
q_{t}=k_{\text {in }}\left(t^{\frac{1}{2}}\right)
$$

The stages of the intra-particle diffusion kinetics for the concentration of $10 \mathrm{mg} . \mathrm{L}^{-1}$ are displayed in Figure 3 and the parameters are displayed in Table 1. These graphs exhibit multilinearity, which indicates the occurrence of two or more controlling steps. The low correlation coefficients in the kinetic model of intra-particle diffusion demonstrate that the adsorption process is governed by the transference of external mass, with the pseudo-second order kinetics serving as the controlling step. (Wu et al., 2001; Ulson de Souza et al., 2012).

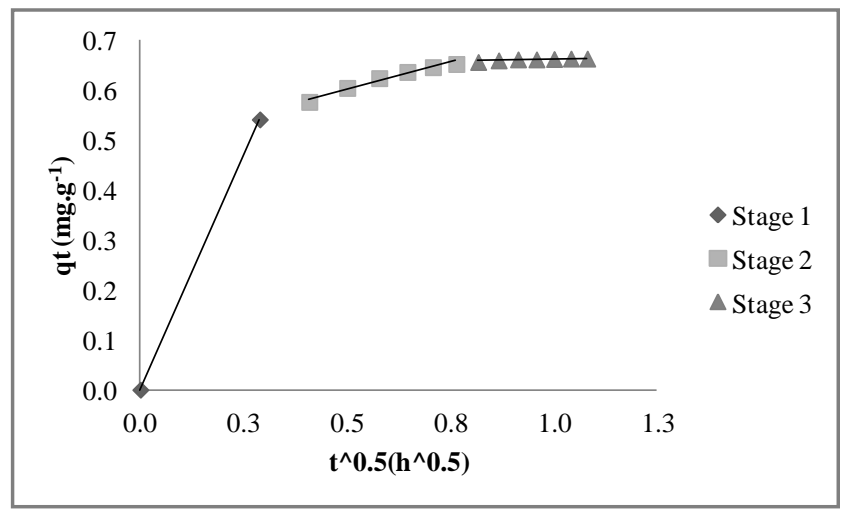

Figure 3 - Intra-particle diffusion at concentration of $10 \mathrm{mg} / \mathrm{L}$ (Stage 1: instantaneous adsorption; Stage 2: gradual adsorption; Stage 3: final equilibrium).

\subsection{Thermodynamic study}

Adsorption diminished with the increase in temperature, shown in Figure 4a, indicating an exothermic process with the release of heat during adsorption (GUPTA et al., 2010). Adsorption isotherms are important to the description of how an absorbate would interact with an adsorbent and the determination of whether adsorption would be efficient.

The Langmuir model proposes that adsorption occurs on homogeneous surfaces that contain a finite number of identical adsorption sites without any interaction among the adsorbed molecules, (Salam et al., 2011; Karthikeyan et al., 2005), following Equation 5, in which $b$ is a constant related to the adsorption energy, $q_{\max }$ is the maximum adsorption, $q_{e}$ is the amount of solute adsorbed and $C_{e}$ is the equilibrium concentration. The $R_{L}$ values may indicate an unfavorable $\left(R_{L}>1\right)$, linear $\left(R_{L}=1\right)$, favorable $\left(0<R_{L}<1\right)$ or irreversible $\left(R_{L}=0\right)$ isotherm, displayed in Table 7, following Equation 6. (Radnia et al., 2011).

$$
q_{e}=\frac{q_{\max } b C_{e}}{\left(1+b C_{e}\right)} \quad, \quad R_{L}=\frac{1}{\left(1+b C_{o}\right)}
$$

Freundlich suggesting a multisite adsorption model for heterogeneous surfaces, the amount of material adsorbed is the sum of the adsorption at all sites (Karthikeyan et al., 1991), Equation 7 following the model, in which $k_{F}$ and $n_{F}$ are the empirical Freundlich parameters. 


$$
q_{e}=k_{F} C_{e}^{1 / n F}, \quad q_{e}=\frac{q_{m_{L F}} b_{L F} C_{e}^{m_{L F}}}{1+b_{L F} C_{e}^{m_{L F}}}
$$

The Langmuir-Freundlich equation was designed based on a modification of the Langmuir equation by the inclusion of an expression from the Freundlich equation. This model unites equations 5 and 7 to represent results better (Equation 8), in which $b$ is an equilibrium constant of the model for a heterogeneous solid and $m_{L F}$ is the heterogeneity parameter between 0 and 1. (Subramanyam and Ashutosh, 2012).

Figure $4 \mathrm{~b}$ display the $\mathrm{Cr}(\mathrm{VI})$ adsorption isotherms following the Langmuir, Freundlich and Langmuir-Freundlich models at $298 \mathrm{~K}$. Table 2 displays the parameters of each isotherm model.

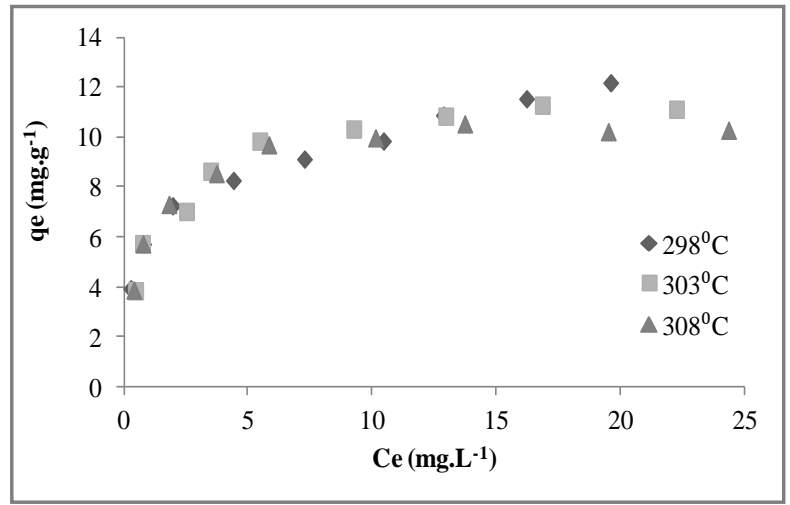

(a)

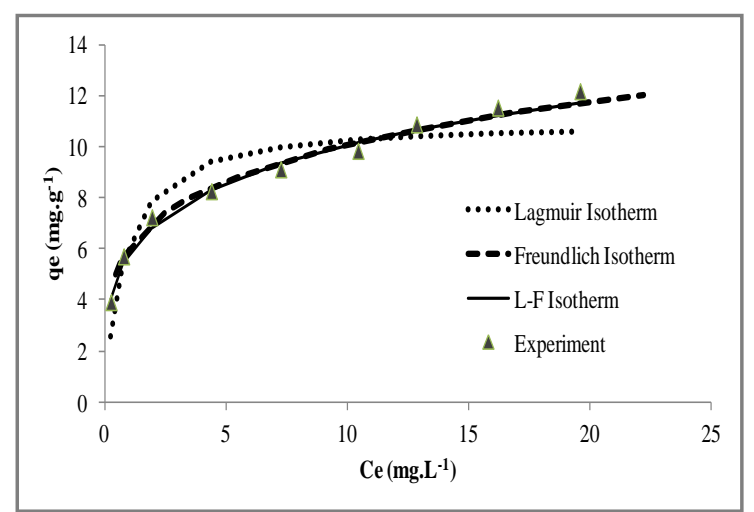

(b)

Figure 4 - Representation of $\mathrm{Cr}(\mathrm{VI})$ adsorption isotherms $\mathrm{W}=0.5 \mathrm{~g}$ and $135 \mathrm{rpm}$, at different temperatures (a), at $298 \mathrm{~K}(\mathrm{~b})$

As seen in Table 2, findings indicate that adsorption is better fit for LangmuirFreundlich equation $\left(\mathrm{R}^{2}=0.99\right)$ with a $q_{\max }$ of $67.46 \mathrm{mg} \cdot \mathrm{g}^{-1}$, suggesting a heterogeneous surface with a wide gamut of affinities to binding sites, with the possible occurrence of a duo or multilayer (Umpleby et al., 2001). The $\mathrm{R}_{\mathrm{L}}$ factor was between 0 and 1 indicating favorable adsorption. Few previous studies have achieved similar results for metal ions. In a study on chitosan used to adsorb $\mathrm{Fe}(\mathrm{II})$, the Langmuir-Freundlich model exhibited the best fit to the experimental results $\left(R^{2}=0.9972, q_{\max }=80.27 \mathrm{mg} \cdot \mathrm{g}^{-1}\right)($ Radnia et al., 2011).

Table 2 - Parameters of Langmuir, Freundlich and Langmuir/Freundlich isotherms

\begin{tabular}{|c|c|c|c|c|c|c|c|c|c|c|c|c|}
\hline \multirow[b]{2}{*}{$\begin{array}{c}\mathrm{T} \\
(\mathrm{K})\end{array}$} & \multicolumn{4}{|c|}{ Langmuir } & \multicolumn{4}{|c|}{ Freundlich constants } & \multicolumn{4}{|c|}{ Langmuir-Freundlich constants } \\
\hline & $\begin{array}{l}q_{\max } \\
\left(m g . g^{-1}\right.\end{array}$ & $R_{L}$ & $\begin{array}{l}b \\
\left(L . m g^{l}\right)\end{array}$ & $R^{2}$ & $1 . n^{-1}$ & $N$ & $K_{F}$ & $R^{2}$ & $\begin{array}{l}q_{\max } \\
\left(m g \cdot g^{-1}\right)\end{array}$ & $\begin{array}{l}b \\
\left(L . m g^{-1}\right)\end{array}$ & $m_{L F}$ & $R^{2}$ \\
\hline 298 & 11.03 & & 1.294 & & & & & & 6746 & 0.094 & & .98 \\
\hline 303 & 11 & 0 & 1 & 0.9 & 0.22 & 4. & 6.0 & 0. & 13.26 & 0.789 & 4 & 0.99 \\
\hline 308 & 10.61 & 0.064 & 1.467 & 0.98 & 0.182 & 5.465 & 6.249 & 0.94 & 11.02 & 1.306 & 0.843 & 0.99 \\
\hline
\end{tabular}

$* R_{L}$ for $\mathrm{Cr}(\mathrm{VI})$ concentration of $10 \mathrm{mg} . \mathrm{L}^{-1}$

Thermodynamic parameters, such as $\Delta H^{\circ}$ (change in enthalpy) and $\Delta S^{\circ}$ (change in entropy), were calculated using the $\ln b$ versus $1 . \mathrm{T}^{-1}$ plot with the parameters of the LangmuirFreundlich isotherm. Equation 9 was used to fit the experimental data and the linear 
correlation coefficient was $0.8934 . \Delta G^{\circ}$ (change in Gibb's free energy) was calculated using Equation 10 (Meena et al., 2005), in which $R$ is $8.314 \mathrm{~J} \mathrm{~mol}^{-1} \mathrm{~K}^{-1}, T$ is in $K$ and $b\left(\mathrm{~L}_{\mathrm{mg}} \mathrm{m}^{-1}\right)$ is the thermodynamic equilibrium constant defined by $q_{e} / C_{e}$.

$$
\ln b=-\frac{\Delta H^{\circ}}{R T}+\frac{\Delta S^{\circ}}{R}, \quad \Delta G^{\circ}=\Delta H^{\circ}-T \Delta S^{\circ}
$$

Table 3 - Thermodynamic parameters for Cr(VI) adsorption to coconut shell charcoal

\begin{tabular}{|c|c|c|c|}
\hline $\mathrm{T}(\mathrm{K})$ & $\Delta \mathrm{G}^{\circ}\left(\mathrm{kJ} \cdot \mathrm{mol}^{-1}\right)$ & $\Delta \mathrm{H}^{\circ}\left(\mathrm{kJ} \cdot \mathrm{mol}^{-1}\right)$ & $\Delta \mathrm{S}^{\circ}\left(\mathrm{kJ} \cdot \mathrm{mol}^{-1} \mathrm{~K}^{-1}\right)$ \\
\hline 298 & 5.212 & & \multirow{2}{*}{201.464} \\
\hline 303 & 1.924 & & 0.658 \\
\hline 308 & -1.368 & & \\
\hline
\end{tabular}

Table 3 displays a positive $\Delta S^{\circ}$ value indicating that $\mathrm{Cr}(\mathrm{VI})$ adsorption process caused disorder in the system. The negative $\Delta G^{\circ}$ indicates a spontaneous nature and energetic favorability of the adsorption of the ion to the adsorbent. The reduction in $\Delta G^{\circ}$ with the increase in temperature demonstrates that adsorption is favored at lower temperatures, thereby confirming the exothermic process. Previous studies have achieved similar results, as $\mathrm{Ni}$ (II) adsorption on Aerogel Charcoal, Meena et al., 2005, obtained a positive $\Delta S^{\circ}$ value $(0.16$ $\mathrm{kJ} . \mathrm{mol}^{-1} \mathrm{~K}^{-1}$ ) and negative $\Delta G^{\circ} 3.73$ to $-2.67 \mathrm{~kJ}^{\circ} \mathrm{mol}^{-1}$ with temperature from 293 to $333 \mathrm{~K}$, and the same study with $\mathrm{Cu}(\mathrm{II})$ adsorption obtained a positive $\Delta S^{\circ}$ value $\left(0.09 \mathrm{~kJ} \cdot \mathrm{mol}^{-1} \mathrm{~K}^{-1}\right)$ and negative $\Delta G^{\circ} 1,44$ to $-2.42\left(\mathrm{~kJ} . \mathrm{mol}^{-1}\right)$.

\section{CONCLUSION}

Thermally and chemically activated CSC proved efficient for the removal of high concentrations of $\mathrm{Cr}(\mathrm{VI})$ from aqueous solution. Adsorption was weakly dependent on the $\mathrm{pH}$ of the solution, allowing the use of the natural $\mathrm{pH}$ of the solution to obtain an effective reduction in the amount of $\mathrm{Cr}(\mathrm{VI})$ in an aqueous solution. The Langmuir-Freundlich model, which has previously been little used for modeling the phenomenon of metal ion adsorption, best described the equilibrium between the adsorbent and adsorbate. The pseudo-second order kinetic model achieved the best correlation coefficient for the three concentrations studied. The chemical surface between the adsorbate and adsorbent proved important to the adequate adsorption of $\mathrm{Cr}(\mathrm{VI})$ ions, as adsorption was enhanced following the chemical treatment of the adsorbent. The thermodynamic study indicates the viability of the adsorbent and the spontaneity of the adsorption process and that the $\mathrm{Cr}(\mathrm{VI})$ adsorption process caused disorder in the system.

\section{REFERENCES}

AL-OTHMAN, Z.A., ALI, R., NAUSHAD. M. Hexavalent chromium removal from aqueous, solution medium by activated carbon prepared from peanut shell: Adsorption kinetics, equilibrium and thermodynamic studies, Chem. Eng. J. 184, 238-247 (2012).

ANANDKUMAR, J., MANDAL, B. Removal of Cr(VI) from aqueous solution using Bael fruit (Aegle marmelos correa) shell as an adsorbent, J. Hazard. Mater. 168, 633-640 (2009).

BOEHM, H. P. Surface oxides on carbon and their analysis: a critical assessment, Carbon, 40, 145-149 (2002). 
DURANOGLU, D., TROCHIMCZUK, A.W., BEKER, U. Kinetics and thermodynamics of hexavalent chromium adsorption onto activated carbon derived from acrylonitriledivinylbenzene copolymer, Chem. Eng. J. 187, 193-202 (2012).

GUPTA, V.K., RASTOGI, A., NAYAK, A. Adsorption studies on the removal of hexavalent chromium from aqueous solution using a low cost fertilizer industry waste material, $J$. Colloid Interface Sci. 342, 135-141 (2010).

JING, G., ZUOMING, Z., SONG, L.S., DONG, M. Ultrasound enhanced adsorption and desorption of chromium(VI) on activated carbon and polymeric resin, Desalination, 279, 423-427 (2011).

KARTHIKEYAN, T., RAJGOPAL, S., MIRANDA, L.R. Chromium adsorption from aqueous solution by Hevea Brazilinesis sawdust activated carbon, J. Hazard. Mater. B124, 192-199 (2005).

KOBYA, M., DEMIRBAS, E., SENTUR, E., INCE, M. Adsorption of heavy metal ions from aqueous solutions by activated carbon prepared from apricot stone, Bioresour. Technol. 96, 1518-1521 (2005).

MEENA, A.K., MISHRA, G.K., RAI, P.K., RAJAGOPAL, C., NAGAR, P.N. Removal of heavy metal ions from aqueous solution using carbon aerogel as an adsorbent, $J$. Hazard. Mater. 122, 161-170 (2005).

MOHAN, S., GANDHIMATHI, R. Removal of heavy metal ions from municipal solid waste leachate using coal fly ash as an adsorbent, J. Hazard. Mater. 169, 351-359 (2009).

PARK, D., LIM, S.R., YUN, Y.S., PARK, J.M. Reliable evidences that the removal mechanism of hexavalent chromium by natural biomaterials is adsorption-coupled reduction, Chemosphere. 70, 298-305 (2007).

RADNIA, H., GHOREYSHI, A.A, YOUNESI, H. Isotherm and kinetics of Fe(II) Adsorption onto Chitosan in a batch process, Iranica J. Energy e Environ. 3, 250-257 (2011).

RICHTER, C.A., NETTO, J.M.A. Tratamento de água: Tecnologia atualizada, Blucher, São Paulo, (1991).

SALAM, O.E.A., REIAD, N.A., ELSFAFEI, M.M. A study of removal characteristics of heavy metals from wastewater by low-cost adsorvents, J. Adv. Res. 2, 297-303 (2011).

SUBRAMANYAM, B., ASHUTOSH, D. Adsorption Isotherm Modeling of Phenol Onto Natural soils - Applicability of Various Isotherm Models, Int. J. Environ. Res. 6, 265276 (2012).

ULSON DE SOUZA, S.M.A.G., LUZ, A. D., SILVA, A., UlSON DE SOUZA, A.A. Removal of Mono- and Multicomponent BTX Compounds from Effluents Using Activated Carbon from Coconut Shell as the Adsorbent, Ind. Eng. Chem. Res. 51, 6461-6469 (2012).

UMPLEBY, R.J., BAXTER, S.C., CHEN, Y., SHAH, R.N., SHIMIZU, K.D. Characterization of molecularly imprinted polymers with the Langmuir-Freundlich isotherm, Anal. Chem. 73, 4584-4591 (2001).

WAN NGAH, W.S., HANAFIAH, M.A.K.A. Removal of heavy metal ions from wastewater by chemically modified plant wastes as adsorbent: A review, Bioresour. Technol. 99, 3935-3948 (2008).

WU, F.-C., TSENG, R.-L., JUANG, R.-S. Kinetic modeling of liquid-phase adsorption of reactive dyes and metal ions on chitosan, Water Res. 35, 613-618 (2001). 